\title{
Patient satisfaction in the emergency department: a case of Sina hospital in Tabriz
}

\author{
Maryam Eshghi ${ }^{1}$, Farzad Rahmani ${ }^{2 *}$, Behjat Derakhti ${ }^{3}$, Navideh Robai ${ }^{3}$, Fariba Abdollahi ${ }^{3}$, Shahrad Tajoddini ${ }^{4}$
}

'Department of Internal Medicine, Tabriz branch, Islamic Azad University, Tabriz, Iran ${ }^{2}$ Road Traffic Injury Research Center, Tabriz University of Medical Sciences, Tabriz, Iran ${ }^{3}$ Department of Emergency Medicine, Tabriz University of Medical Sciences, Tabriz, Iran

${ }^{4}$ Kerman Neuroscience Research Center, Kerman University of Medical Sciences, Kerman, Iran

Received: 20 July 2015

Accepted: 18 August 2015

Published online: 17 October 2015

*Corresponding author: Farzad Rahmani, Department of Emergency Medicine, Tabriz University of Medical Sciences, Tabriz, Iran. Tel: +98-4133352078, Fax: +984133352078 ,

Email: rahmanif@tbzmed.ac.ir

Competing interests: None.

Funding information: None.

Citation: Eshghi M, Rahmani F, Derakhti B, Robai N, Abdollahi F, Tajoddini S. Patient satisfaction in the emergency department: a case of Sina hospital in Tabriz. Journal of Emergency Practice and Trauma 2016; 2(1): 16-20. doi: 10.15171/ jept.2015.06

\begin{abstract}
Objective: Patient satisfaction is one of the most important indicators for measuring the quality of emergency services and health care. The purpose of this study was to evaluate the patients' satisfaction in the emergency department (ED) of Sina hospital.

Methods: This descriptive, cross-sectional study was performed during one month in Sina hospital in 2014. Data were collected by a questionnaire which its validity and reliability were confirmed in previous studies. The questionnaire consisted of 2 parts. Part 1 included the demographic characteristics and part 2 encompassed the scales of satisfactory. Data analysis was conducted by SPSS version 15 .

Results: Totally, 425 patients participated in this study. The mean age of patients was $41.6 \pm 17.6$ years. The mean total score of patient satisfaction was $17.43 \pm 1.56$. The maximum satisfaction was related to the knowledge of physicians and the minimum satisfaction was related to the remaining period in the ED. Additionally, there was a desirable satisfaction for nurses' performances. In terms of satisfaction regarding the physical environment and the workflow of the ED, the results were moderate. There was a significant statistical difference regarding nurses and physicians behavior in the ED during different working shifts, vacation days, and workdays.

Conclusion: Based on the results obtained, patients had good satisfaction for the received services in the ED. It is necessary to develop physical spaces and improve the workflow of patients in the ED.
\end{abstract}

Keywords: Patient Satisfaction, Emergency Service, Hospital

\section{Introduction}

Among the departments and agencies responsible for providing the health, hospitals play a pivotal role in the delivery of services regarding human lives (1). The hospital emergency department (ED) can be considered as a standalone entity to provide full outpatient and inpatient services (2). The role of ED as a service providing system is undeniable as it has an effect on patients' satisfaction for the therapeutic services they provide. The ED is not only the first therapeutic department to provide the services to many patients but also it is considered as a place for performing many therapeutic programs and clinical procedures (3).

In this context, by evaluating patients' satisfaction regarding the services they receive in the $\mathrm{ED}$, the quality of services can be judged. Thus, decision makers and managers can better provide and design the programs for the pa- tients in the ED (4).

In addition, the pitfalls of programs and the weaknesses of clinical protocols can be identified. In this regard, the health care delivery system can better provide its services to the patients $(5,6)$.

Soleimanpour et al (7) stated that factors such as nurses' and doctors' behavior and the waiting time to visit the doctor play a part in the satisfaction of patients in the ED. In another study by Zahmatkesh et al (8), it was found that educating staff how to behave with patients especially in their interpersonal relationship was an important matter affecting the quality of services.

Therefore, patient satisfaction is one of the most important indicators of the quality of emergency care (9-11) and health care outcomes (12). Generally, an increased satisfaction for the services in the ED may have a significant impact on patients' attitudes toward the hospital's 
ED and emergency care (13). Nowadays EDs consider patients' satisfaction as an important subject than before (14). However, hospital emergency units face many challenges that can lead to a decrease for the satisfaction of patients (15).

Based on the importance of patients' satisfaction in the ED, we conducted this study to evaluate patients' satisfaction in the ED of Sina hospital in Tabriz. In our study various criteria are taken into account regarding patients' satisfaction and recommendations are made as well.

\section{Methods}

In this descriptive cross-sectional study, 425 patients who referred to the ED of Sina hospital in Tabriz between November and December 2014 participated. The Morgan table was used for determining the sample size by considering $\alpha=0.05, \mathrm{CI}=0.95$, and the number of monthly visits at 3500. In this run, the sample size was 346. For accuracy purposes, we increased the sample size to 425 . All patients who referred to the ED of Sina hospital during the study period were included. Exclusion criteria included any cognitive impairment (impaired attention, recent memory impairment, lack of understanding of the questionnaire items), inability of patients to respond to the questionnaire due to their unstable general condition, and refraining from signing the consent form. The study conditions were explained to the patients and their companions, and the written informed consent was obtained. The data gathering tool was a questionnaire in which its validity and reliability were confirmed in previous studies (16). The questionnaire was composed of two main parts. The first part included demographic characteristics (age, sex, level of education, place of residence, marital status), referring shifts to ED (morning, afternoon, evening), the day of visiting the ED (holiday, workday), disease types (internal medicine, surgery, dermatology, infectious diseases) and determining the outcome of emergency (admission, discharge, dispatch, death). The second part contained variables related to satisfaction on a 5-point Likert scale $(1=$ very poor and $5=$ very good). This part of the questionnaire included 25 items and a total of 4 subscales that each subscale consisted of 5 options for answers. Satisfaction questionnaire included several variables that were about the physicians (6 questions), nurses (4 items), physical space (8 questions), the workflow in the ED (5 questions), and miscellaneous ( 2 items). To increase the accuracy of the questionnaire, a number of negative questions were added to the questionnaire (the workflow section). In this case the desired results were weak and very weak options. In order to analyze the results, researchers calculated the sum of scores and interpreted them as favorable (75\%-100\%), average satisfaction (50\%-74\%), and unfavorable (50\%). Finally, at the end of the questionnaire, patients were asked to rate their overall satisfaction for the ED with scores of 0 to 20. Questionnaires were filled out by patients in collaboration with a researcher who was not part of the medical staff and the ED department. In order to analyze data, descriptive tests (frequency, mean, and standard deviation) as well as analytical tests (chi-square) were conducted. SPSS version 15 was used for data analysis. $\mathrm{P}$ value less than 0.05 was considered as significant.

\section{Results}

Totally, 425 patients participated in the study. A total of 229 patients were male and 196 were female. The mean age of the patients was $41.6 \pm 17.6 .367$ patients were from urban areas and 58 patients were from rural areas. 116 patients were married and 309 were single. Regarding the patients' education, $24.9 \%$ were uneducated, $11.3 \%$ had basic education, $13.2 \%$ had middle education, $32.5 \%$ had diploma or a higher degree, and $14.1 \%$ had BA or a higher degree $(14.1 \%)$.

136 patients (32\%), 108 patients $(25.4 \%)$, and 181 patients (42.6\%) were referred to the ED in morning, afternoon, and night shifts respectively. Also, the number of patients in the workdays was 140 (32.9\%) and in the vacation days was 285 patients $(67.1 \%)$.

In terms of disease types, internal medicine, surgery, skin diseases, and infectious diseases were at 56.7\%, 31.5\%, $8 \%$, and $3.8 \%$ respectively. In terms of the final condition of patients, $50.1 \%$ were discharged, $48 \%$ were hospitalized, and $1.9 \%$ were referred to other health care centers. Table 1 shows the results of patients' satisfaction with different variables. Concerning statements related to physicians, all variables were desirable except "Understanding the terminology used by physician (62.1\%)" and "Description of the disease and required procedures (69.7\%)". With regard to statements related to nurses, this category was at a desirable level. About the physical space, this category was on an average level of satisfaction (the highest level of satisfaction was for cleanliness at $72.4 \%$ and the lowest level of satisfaction was for the ED's toilets at 52.8\%). It should be noted that 42 patients did not use the toilets and therefore they did not respond to this question. The satisfaction level of workflow in the ED of Sina hospital was at a moderate level, while delay for visiting the doctors (67.2\%) had the highest and the length of stay in ED (52\%) had the lowest level of satisfaction.

The behavior of emergency guards (70.6\%) and responding to objections and complaints $(63.1 \%)$ were at a moderate level. The total mean score for patients' satisfaction was $17.43 \pm 1.56$.

In order to compare patients' satisfaction with morning, evening, and night shifts, the Chi square test was used. In this regard, the following significant results were obtained: physicians' care (0.026), physicians' behavior (0.04), physicians' interest to work (0.029), the description of the disease and required procedures (0.01), nurses' behavior (0.013), the discipline of ED (0.001), the calm environment of ED (0.007), delay in filling out the forms (0.028), delay in physicians' visit (0.041), delay in discharge after 
Table 1. Patients' opinions about ED satisfaction

\begin{tabular}{|c|c|c|c|c|c|}
\hline \multirow{2}{*}{ Variables } & Very good & Good & Moderate & Poor & Very poor \\
\hline & No. (\%) & No. (\%) & No. (\%) & No. (\%) & No. (\%) \\
\hline \multicolumn{6}{|l|}{ Variables related to physicians } \\
\hline Physicians care & $172(40.5)$ & $168(39.5)$ & $62(14.6)$ & $21(4.9)$ & $2(0.5)$ \\
\hline Physicians knowledge \& practice & $160(27.6)$ & $214(50.4)$ & $38(8.9)$ & $13(3.1)$ & $0(0)$ \\
\hline Description of the disease and required procedures & $130(30.6)$ & $166(39.1)$ & $91(21.4)$ & $34(8.0)$ & $4(0.9)$ \\
\hline Physician behavior & $162(38.1)$ & $164(38.6)$ & $78(18.4)$ & $19(4.5)$ & $2(0.5)$ \\
\hline Physician's interest to work & $154(36.2)$ & $182(42.8)$ & $74(17.4)$ & $12(2.8)$ & $3(0.7)$ \\
\hline Understanding the terminology used by physician & $120(28.2)$ & $144(33.9)$ & $108(25.4)$ & $43(10.1)$ & $10(2.3)$ \\
\hline \multicolumn{6}{|l|}{ Variables related to nurses } \\
\hline Nursing care & $161(37.9)$ & $192(45.5)$ & $52(12.2)$ & $18(4.2)$ & $2(0.5)$ \\
\hline Nursing knowledge \& practice & $149(35.1)$ & $191(44.9)$ & $74(17.4)$ & $10(2.4)$ & $1(0.2)$ \\
\hline Nursing behavior & $158(37.2)$ & $183(43.1)$ & $60(14.1)$ & $21(4.9)$ & $3(0.7)$ \\
\hline Nurse's interest to work & $160(37.6)$ & $185(43.5)$ & $63(14.8)$ & $15(3.5)$ & $2(0.5)$ \\
\hline \multicolumn{6}{|l|}{ Variables related to ED physical space } \\
\hline Cleaning status of department & $106(24.9)$ & $202(47.5)$ & $103(24.2)$ & $13(3.1)$ & $0(0)$ \\
\hline Status of department WCa & $72(16.9)$ & $154(36.2)$ & $111(26.1)$ & $41(9.6)$ & $5(1.2)$ \\
\hline Status of facilities available in the waiting room & $86(20.2)$ & $153(36.0)$ & $98(23.1)$ & $76(17.9)$ & $14(3.3)$ \\
\hline Status of beds and bed linens & $83(19.5)$ & $170(40.0)$ & $118(27.8)$ & $49(11.5)$ & $3(0.7)$ \\
\hline Discipline status & $95(22.4)$ & $174(40.9)$ & $123(28.9)$ & $26(6.1)$ & $7(1.6)$ \\
\hline Ventilation and temperature status & $101(23.8)$ & $160(37.6)$ & $109(25.6)$ & $45(10.6)$ & $10(2.4)$ \\
\hline Separation of male and female patients & $117(27.5)$ & $178(42.1)$ & 79 (18.6) & $42(9.9)$ & $8(1.9)$ \\
\hline Tranquility status of department & $83(19.5)$ & $162(38.1)$ & $127(29.9)$ & $34(8.0)$ & $19(4.5)$ \\
\hline \multicolumn{6}{|l|}{ Variables related to patients workflow } \\
\hline Delay in filling out the form & $11(2.6)$ & $36(8.5)$ & $103(24.3)$ & $185(43.5)$ & $90(21.2)$ \\
\hline Delay in physician visit & $11(2.6)$ & $30(7.1)$ & $97(22.8)$ & $177(41.6)$ & $109(25.6)$ \\
\hline Delay in discharge after disposition & $14(3.3)$ & $44(10.4)$ & $121(28.4)$ & $155(36.5)$ & $92(21.6)$ \\
\hline Paraclinic problems (labs or imaging) ${ }^{\mathrm{b}}$ & $7(1.6)$ & $39(9.2)$ & $91(21.4)$ & $145(34.1)$ & $101(23.8)$ \\
\hline Length of stay in emergency department & $136(32.0)$ & $85(20.0)$ & $119(28.0)$ & $51(12.0)$ & $34(8.0)$ \\
\hline \multicolumn{6}{|l|}{ Miscellaneous variables } \\
\hline Responding to objections and complaints & $84(19.8)$ & $184(43.3)$ & $112(26.4)$ & $34(8.0)$ & $11(2.6)$ \\
\hline Guard misbehavior with patient and his/her families & $6(1.4)$ & $35(8.2)$ & $84(19.8)$ & $184(43.3)$ & $116(27.3)$ \\
\hline
\end{tabular}

${ }^{a} 42$ patients had not used the WC and did not answer the question.

${ }^{b} 42$ patients had not used the paraclinical services and did not answer the question.

disposition (0.013), and paraclinic problems (labs or imaging) (0.037). In other cases, there was not a significant relationship.

In order to compare patients' satisfaction with workdays and vacation days, the chi-square test was used. The significant cases included physicians' care (0.005), physicians' behavior (0.001), and nurses' behavior (0.038). In other cases, there was not a significant relationship.

\section{Discussion}

EDs play an important role in providing health care services to patients. Thus patients' satisfaction regarding the ED services is crucial as they are the first place of treatment for many patients (3).

Patient satisfaction in the ED is considered as an indica- tor to assess the quality of care provided by the staff of this department (10). It should be mentioned that the relationship between satisfaction and the quality of care is complex and it is affected by patients, physicians, and the service providers (17). Patients' expectation of health care services has an impact on their satisfaction $(18,19)$. The mismatch between patients' expectations and received services leads to lower satisfaction (12). Patients with high and impossible expectations may be dissatisfied from optimal care, whereas patients with low expectations, even with partial care, may be satisfied (18).

In our study, the overall satisfaction score was good. The physical space of the ED in Sina hospital is under construction and a temporary location is used for providing health care services. Although the number of patients is 
increasing every day but the number of medical staff is fairly constant, thus, it has an effect on the quality of provided services. The results of this study showed that the satisfaction level for different shifts and during vacation days and workdays were significantly different. This can be due to the increased number of patients in the evening and night shifts as well as closed hospital outpatient clinics on holidays. Several studies have been conducted to assess patient satisfaction in hospitals. Jennings et al concluded that patients' satisfaction regarding ED's nurses was more favorable than ED's doctors (20). Soleimanpour et al (7) concluded that 2 contributing factors play a part in patients' satisfaction. These were the care provided by nurses and doctors and the appointment waiting times. In a study by Sarchami and Sheikhi (21) it was found that $98.4 \%$ of patients were satisfied with the provided services in the ED. In this study, satisfaction of women was more than men and the age group of 30 to 39 had the highest level of service satisfaction.

In our study, regarding physicians, maximum satisfaction was related to physicians' behavior and the minimum satisfaction was related to the description of disease and required procedures. With regard to nurses, all factors had a desirable status. In addition, physical space and workflow had a moderate satisfaction status.

\section{Conclusion}

Based on the results of this study, it can be concluded that the ED of Sina Hospital should be improved both physically and in terms of staff and services to increase patients' satisfaction. In this regard, providing a bigger area, increasing the number of beds, building an observation unit for the comfort of patients who stay a long time in the ED, constructing an outpatient clinic to reduce the number of patients admitted to the main section of ED, increasing the amenities in the emergency waiting room for patients' families, and supervising the cleanliness of wards and toilets are essential. Additionally, in order to maximize the satisfaction of patients it is necessary to increase the number of staff and services. We suggest that triage nurses at first explain the workflow of the ED to the patients so that they would not be dissatisfied from the long-term residency in the ED. Further studies are also recommended to compare the results of this study.

\section{Acknowledgments}

We express our sincere thanks to all colleagues and patients who participated in this research.

\section{Authors' Contributions}

$\mathrm{ME}, \mathrm{BD}$, and NR participated in data collection. FR and FA performed literature review, and drafted the manuscript. All authors were involved in either managing the patient or writing the manuscript. All authors read and approved the final manuscript

\section{References}

1. Sheikhi MR, Javadi A. Patients' satisfaction of medical services in Qazvin education hospitals. The Journal of Qazvin University of Medical Sciences and Health Services 2004; 7(5): 62-6. [In Persian].

2. Feied CF, Smith MS, Handler JA, Kanhouwa M. Emergency medicine can play a leadership role in enterprise-wide clinical information systems. Ann Emerg Med 2000; 35(2): 162-7.

3. Hall MF, Press I. Keys to patient satisfaction in the emergency department: results of a multiple facility study. Hosp Health Serv Adm 1996; 41(4): 515-32.

4. Sullivan M. The new subjective medicine: taking the patient's point of view on health care and health. Soc Sci Med 2003; 56(7): 1595-604.

5. Jackson JL, Chamberlin J, Kroenke K. Predictors of patient satisfaction. Soc Sci Med 2001; 52(4): 609-20.

6. Traverso ML, Salamano M, Botta C, Colautti M, Palchik V, Pérez B. Questionnaire to assess patient satisfaction with pharmaceutical care in Spanish language. Int J Qual Health Care 2007; 19(4): 217-24.

7. Soleimanpour H, Gholipouri C, Salarilak S, Raoufi P, Vahidi RG, Rouhi AJ, et al. Emergency department patient satisfaction survey in Imam Reza hospital, Tabriz, Iran. Int J Emerg Med 2011; 4: 2. doi: 10.1186/1865-1380-1-2

8. Zahmatkesh H, Hajimoradloo N, Kazemi Malekmahmoodi S, Khoddam H. The assessment of patients satisfaction of hospital emergency department-Golestan, Iran. Journal of Gorgan University of Medical Sciences 2010; 12(3): 92-6. [In Persian].

9. Boudreaux ED, Mandry CV, Wood K. Patient satisfaction data as a quality indicator: a tale of two emergency departments. Acad Emerg Med 2003; 10(3): 261-8.

10. Trout A, Magnusson AR, Hedges JR. Patient satisfaction investigations and the emergency department. What does the literature say? Acad Emerg Med 2000; 7(6): 695-709.

11. Blumenthal D. Part 1: Quality of care--what is it? N Engl J Med 1996; 335(12): 891-94.

12. McKinley RK, Roberts C. Patient satisfaction with out of hours primary medical care. Qual Health Care 2001; 10(1): 23-28. doi: 10.1136/qhc.10.1.23.

13. Carrasquillo O, Orav EJ, Brennan TA, Burstin HR. Impact of language barriers on patient satisfaction in an emergency department. J Gen Intern Med 1999; 14(2): 82-7.

14. Lau FL. Can communication skills workshops for emergency department doctors improve patient satisfaction? J Accid Emerg Med 2000; 17(4): 251-3. doi: 10.1136/emj.17.4.251.

15. Fenton JJ, Jerant AF, Bertakis KD, Franks P. The cost of satisfaction: a national study of patient satisfaction, health care utilization, expenditures, and mortality. 
Arch Intern Med 2012; 172(5): 405-11. doi: 10.1001/ archinternmed.2011.1662.

16. Omidvari S, Shahidzadeh Mahani A, Montazeri A, Azin SA, Harirchi AM, Soori H, et al. Patient satisfaction with emergency departments. Payesh Journal 2008; 7(2):141-152. [In Persian].

17. Kinnersley P, Anderson E, Parry K, Clement J, Archard L, Turton P, et al. Randomised controlled trial of nurse practitioner versus general practitioner care for patients requesting "same day" consultations in primary care. BMJ 2000; 320(7241): 1043-8.

18. McKinley RK, Stevenson K, Adams S, MankuScott TK. Meeting patient expectations of care: the major determinant of satisfaction with out-of-hours primary medical care? Fam Pract 2002; 19(4): 333-8.

19. Bryan-Brown CW, Dracup K. Outcomes, endpoints, and expectations. Am J Crit Care 1996; 5(2): 87-9.

20. Jennings N, Lee G, Chao K, Keating S. A survey of patient satisfaction in a metropolitan Emergency Department: comparing nurse practitioners and emergency physicians. Int J Nurs Pract 2009; 15(3): 213-8. doi: 10.1111/j.1440-172X.2009.01746.x.

21. Sarchami R, Sheikhi MR. Patient's satisfaction of quality services in emergency departments. The Journal of Qazvin University of Medical Sciences 2001; 5(2): 64-8. [In Persian]. 